\title{
Effect of IncRNA ANRIL silencing on anoikis and cell cycle in human glioma via microRNA-203a
}

This article was published in the following Dove Press journal:

OncoTargets and Therapy

\section{Weiying Dai* \\ Chao Tian* \\ Song Jin}

Department of Radiology, Tianjin Huanhu Hospital, Tianjin Key Laboratory of Cerebral Vascular and Neurodegenerative Diseases, Tianjin 300350, People's Republic of China

*These authors contributed equally to this work
Correspondence: Song Jin Department of Radiology, Tianjin Huanhu Hospital, Tianjin Key Laboratory of Cerebral Vascular and Neurodegenerative Diseases, 6 Jizhao Road, Jinnan District, Tianjin 300350, People's Republic of China Email jinsongone@sina.com
Background: Glioma is a deadly nervous system tumor with a poor prognosis. Although there have been many efforts to overcome glioma, the molecular mechanism of its pathogenesis remains unclear.

Methods: We used human glioma U251 cells silenced for the oncogenic lncRNA ANRIL or overexpressing the anti-oncogene miR-203a to examine the role of lncRNA ANRIL silencing on anoikis and cell cycle arrest by flow cytometry. Meanwhile, the activity of caspase-3/8/9 was measured by fluorometric assay, the expression of tumor-related genes and activity of AKT signaling pathway was measured by Western blotting, real-time PCR, and dual luciferase reporter gene assay.

Results: IncRNA ANRIL was positively correlated with glioma grade and negatively correlated with miR-203a. IncRNA ANRIL silencing could induce anoikis and cell cycle arrest in G0/G1 phase, while regulating the activity of caspase-3/8/9 and the AKT signaling pathway, and the expression of tumor-related genes in the U251 cell line. miR-203a mimics could partially reverse these functions.

Conclusion: We consider that lncRNA ANRIL is a potential therapeutic and diagnostic target for glioma, and miR-203a plays an important role in the biological function of lncRNA ANRIL in glioma.

Keywords: glioma, long non-coding RNA, anoikis, cell cycle, lncRNA ANRIL, microRNA-203a

\section{Introduction}

Although there have been many efforts to overcome glioma, it remains a significant cause of cancer-related morbidity with poor prognosis in the People's Republic of China. ${ }^{1}$ With the development of molecular biology technology, many studies have explored therapeutics and diagnosis of glioma using novel molecular biological targets.

lncRNAs are a type of non-coding RNA (ncRNA) more than 200 nucleotides in length. ${ }^{2}$ Some reports have shown that lncRNAs can affect the expression of genes and play an important role in the tumorigenesis process. ${ }^{3}$

Some reports have shown that lncRNA ANRIL is associated with osteosarcoma and lung cancer; ${ }^{4,5}$ however, the role of lncRNA ANRIL in glioma has not been fully elucidated. An increased expression of IncRNA ANRIL in glioma correlating with grade and a negative correlation with the anti-oncogene miR-203a has been found; ${ }^{6,7}$ thus, we considered that there may be a potential relationship between lncRNA ANRIL, the glioma tumorigenesis process, and miR-203a expression. This study aimed to explore the effect of IncRNA ANRIL silencing on induced anoikis and cell cycle arrest in human glioma and the possible mechanism involved. 


\section{Materials and methods}

\section{Tissue}

Glioma samples of different grades (World Health Organization [WHO]-II, n=10; WHO-III, n=10; WHO-IV, n=10) were provided by the department of neurosurgery of Tianjin Huanhu Hospital from May 2015 to April 2017. The study was approved by the Ethics Committee of Tianjin Huanhu Hospital and all experiments were performed in accordance with approved guidelines and regulations of the Helsinki Declaration of 1975, as revised in 2008. Written informed consent was obtained from patients for the use of their tissue samples in this research.

\section{Cell line and culture}

Human glioma U251 cell line was provided by The Cell Bank of Type Culture Collection of Chinese Academy of Sciences and cultured in DMEM with 10\% fetal bovine serum, $50 \mathrm{U} / \mathrm{mL}$ penicillin, and $50 \mu \mathrm{g} / \mathrm{mL}$ streptomycin at $37^{\circ} \mathrm{C}, 5 \% \mathrm{CO}_{2}$.

The siRNA pcDNA3.1-ANRIL (si-ANRIL) primer sequence was 5'-GGUCAUCUCAUUGCUCUAU-3', miR-203a mimic (si-miR-203a) was purchased from Thermo Fisher Scientific, Waltham, MA, USA, and empty vector, pcDNA3.1, was used as a negative control (NC) group. Plasmids harboring si-ANRIL, miR-203a, or NC were transfected into glioma U251 cells using Lipofectamine 2000 according to the manufacturer's instructions. The following experiments were performed 72 hours after transfection.

\section{MTS assay}

U251 cells (5,000/well) were seeded in a 96-well plate and cultured for 72 hours at $37^{\circ} \mathrm{C}, 5 \% \mathrm{CO}_{2}$. The medium was then refreshed, MTS was added, and it was cultured for 4 hours at $37^{\circ} \mathrm{C}, 5 \% \mathrm{CO}_{2}$. The OD of the culture was measured at $490 \mathrm{~nm}$ with a microplate reader (Thermo Fisher Scientific).

\section{Anoikis assay}

U251 cells $\left(3 \times 10^{5} /\right.$ well) were seeded in a 6 -well plate coated with Poly-HEMA (2-hydroxyethyl methacrylate) and cultured for 72 hours at $37^{\circ} \mathrm{C}, 5 \% \mathrm{CO}_{2}$. Cells were collected and stained with Annexin V-FITC at room temperature for 15 minutes in the dark. Fluorescence was then measured at $490 \mathrm{~nm}$ with a microplate reader (Thermo Fisher Scientific). PI3K inhibitor LY294002 $(0.5 \mu \mathrm{M})$ was added for 72 hours to observe the effect of anoikis mediated by lncRNA ANRIL.

\section{Caspase-3/8/9 activity assay}

U251 cells $\left(3 \times 10^{5} /\right.$ well) were seeded in a 6 -well plate coated with Poly-HEMA (2-hydroxyethyl methacrylate) and cultured for 72 hours at $37^{\circ} \mathrm{C}, 5 \% \mathrm{CO}_{2}$. Cells were collected, and the activity of caspase-3/8/9 was measured by a Caspase 3, 8, 9 Multiplex Activity Assay Kit (Abcam, Cambridge, MA, USA) and fluorometric assay using a microplate reader (Thermo Fisher Scientific).

\section{Cell cycle assay}

U251 cells $\left(3 \times 10^{5} /\right.$ well $)$ were seeded in a 6 -well plate and cultured for 72 hours at $37^{\circ} \mathrm{C}, 5 \% \mathrm{CO}_{2}$. Cells were collected and fixed with $70 \%$ alcohol at $4{ }^{\circ} \mathrm{C}$ overnight. The alcohol was removed, and cells were suspended in PBS; $200 \mu \mathrm{L}$ propidium iodide $(50 \mu \mathrm{g} / \mathrm{mL})$ and $50 \mu \mathrm{L} \mathrm{RNaseA}(100 \mu \mathrm{g} / \mathrm{mL})$ were then added to the cell suspension at room temperature for 30 minutes in the dark. Fluorescence was measured at $488 \mathrm{~nm}$ with a flow cytometer.

\section{Real-time PCR assay}

U251 cells $\left(3 \times 10^{5} /\right.$ well $)$ were seeded in a 6-well plate and cultured for 72 hours at $37^{\circ} \mathrm{C}, 5 \% \mathrm{CO}_{2}$, and total RNA was extracted by using TRIzol (Invitrogen, Thermo Fisher Scientific). Expression of miR-203a was detected by using the miScript Reverse Transcription Kit (Qiagen NV, Venlo, the Netherlands), and expression of ANRIL and tumor-related genes was detected by using the miScript SYBR Green PCR kit (Qiagen NV) and an ABI 7500 PCR analyzer (Applied Biosystems, Thermo Fisher Scientific). The reaction conditions were initial denaturation at $93^{\circ} \mathrm{C}$ for 1 minute, followed by 40 cycles of denaturation at $93^{\circ} \mathrm{C}$ for 30 seconds, annealing at $65^{\circ} \mathrm{C}$ for 30 seconds, and extension at $72^{\circ} \mathrm{C}$ for 10 minutes, and a final extension at $72^{\circ} \mathrm{C}$ for 5 minutes. GAPDH was used for normalizing ANRIL and tumor-related gene expression, and U6 was used for normalizing miR-203a expression, all using the $2^{-\Delta \Delta \mathrm{Cq}}$ method. Real-time PCR primers are given in Table 1.

\section{Dual luciferase reporter gene assay}

U251 cells ( $3 \times 10^{5} /$ well) were seeded in a 6 -well plate and cultured for 72 hours at $37^{\circ} \mathrm{C}, 5 \% \mathrm{CO}_{2}$. The dual luciferase reporters Twist1 and c-jun were purchased from YRGene (Changsha, People's Republic of China); Renilla Luciferase reporter for normalization was purchased from Promega Corporation (Fitchburg, WI, USA). The luciferase reporters were transfected in glioma U251 cells using Lipofectamine 2000 according to the manufacturer's instructions and cultured for 6 hours at $37^{\circ} \mathrm{C}, 5 \% \mathrm{CO}_{2}$; the medium was then refreshed, and the cells were cultured overnight at $37^{\circ} \mathrm{C}, 5 \% \mathrm{CO}_{2}$. Fluorescence intensity was measured by using a microplate reader (Thermo Scientific) via the Dual-Luciferase ${ }^{\circledR}$ Reporter Assay System (Promega Corporation). 
Table I The real-time PCR primers

\begin{tabular}{ll}
\hline Gene & Primer sequences (5'-3') \\
\hline IncRNA ANRIL & F: TGCTCTATCCGCCAATCAGG \\
R: GGGCCTCAGTGGCACATACC \\
miR-203a & F: GCGTGAAATGTTTAGGACCACT \\
& R: GCTGTCAACGATACGCTACG \\
& RT: GCTGTCAACGATACGCTACGTAACGGC \\
& ATGACAGTGTTTTTTTTTTTTTTTTTTTTTT \\
Bcl-2 & F: ACCTACCCAGCCTCCGTTAT \\
& R: GAACTGGGGGAGGATTGTGG \\
P2I & F: ATTCAGCATTGTGGGAGGAG \\
& R: TGGACTGTTTTCTCTCGGCT \\
CDK2 & F: GGCCTAGCTTTCTGCCATTC \\
& R: CCCAGGAGGATTTCAGGAGC \\
c-myc & F: CGAGGAGAATGTCAAGAGGCG \\
& R: CTGCTTGGACGGACAGGATGT \\
U6 & F: CTCGCTTCGGCAGCACA \\
& R: AACGCTTCACGAATTGCGT \\
GAPDH & F: GTCTCCTCTGACTTCAACAGCG \\
& R: ACCACCCTGTTGCTGTAGCCAA
\end{tabular}

\section{Western blotting}

U251 cells $\left(3 \times 10^{5} /\right.$ well $)$ were seeded in a 6 -well plate and cultured for 72 hours at $37^{\circ} \mathrm{C}, 5 \% \mathrm{CO}_{2}$. Total protein was collected, and the concentration was measured by BCA assay. Fifty nanograms total protein was separated by $10 \%$ SDS-PAGE, transferred to a PVDF membrane, and blocked with 5\% milk at room temperature for 1 hour. After washing with PBST, primary antibody against p21 (1:1,500), Bcl-2 (1:1,500), CDK2 $(1: 1,500)$, c-myc $(1: 1,500)$, p-AKT $(1: 1,500)$, or $\beta$-actin $(1: 4,000)$ was added and incubated overnight at $4^{\circ} \mathrm{C}$. After washing again with PBST, horseradish peroxidase conjugated $\operatorname{IgG}(1: 3,000)$ was added and incubated for 1 hour at $37^{\circ} \mathrm{C}$. An ECL kit (Merck Millipore, Billerica, MA, USA) was used for visualization with $\beta$-actin as the internal reference.

\section{Statistical analysis}

SPSS 11.0 software was used for statistical analysis. Data are expressed as mean $\pm \mathrm{SD}$. Differences between groups were evaluated by one-way analysis of variance. $P<0.05$ was considered significantly different.

\section{Results}

\section{Expression of IncRNA ANRIL and miR-203a in glioma tissues}

We analyzed the expression of $\operatorname{lncRNA}$ ANRIL and miR-203a in glioma tissues and found that there was an increased expression of lncRNA ANRIL in glioma samples with increasing tumor grade (WHO-II, n=10; WHO-III, n=10; WHO-IV, $\mathrm{n}=10$ ) (Figure 1A). The trend in expression of miR-203a was in contrast to that of lncRNA ANRIL (Figure 1B). Further, there was a negative correlation between lncRNA ANRIL and miR-203a in glioma tissues (Figure 1C).

\section{Effect of IncRNA ANRIL silencing on proliferation of human glioma U25 I cells} IncRNA ANRIL silencing could suppress the expression of lncRNA ANRIL and improve the expression of miR-203a; meanwhile, miR-203a mimics suppressed the expression of miR-203a and could not affect the expression of lncRNA ANRIL in U251 cells (Figure 2A and B), indicating that miR-203a may play a role in the function of lncRNA ANRIL. We explored the effect of lncRNA ANRIL silencing on the proliferation of human glioma by MTS assay and found that lncRNA ANRIL silencing could suppress proliferation of U251 cells and that miR-203a mimics could partially reverse this function (Figure 2C).

\section{Effect of IncRNA ANRIL silencing on anoikis and the cell cycle in human glioma U25 I cells}

We explored the effect of lncRNA ANRIL silencing on anoikis and the cell cycle in human glioma, and found that lncRNA ANRIL silencing could induce anoikis and cell cycle arrest in G0/G1 phase in U251 cells and that miR-203a mimics could partially reverse this function. We found that the anoikis induced by lncRNA ANRIL was partially suppressed after PI3K inhibitor LY294002 (0.5 $\mu \mathrm{M})$ was added, indicating the effect of AKT on anoikis mediated by lncRNA ANRIL (Figure 3).

\section{Effect of IncRNA ANRIL silencing on the activity of caspase and expression of tumor-related genes in human glioma U25I cells}

We explored the effect of lncRNA ANRIL silencing on the activity of caspase and the expression of tumor-related genes in human glioma and found that lncRNA ANRIL silencing could improve the activity of caspase-3/8/9 (Figure 4A). Further, lncRNA ANRIL silencing could improve the expression of $\mathrm{p} 21$ while suppressing the expression of Bcl-2, CDK2, c-myc, and p-AKT in U251 cells (Figure 4B and C). At the same time, lncRNA ANRIL silencing could suppress the transcriptional activity of Twist 1 and $c$-jun in U251 cells (Figure 4D); miR-203a mimics could partially reverse this suppression. 

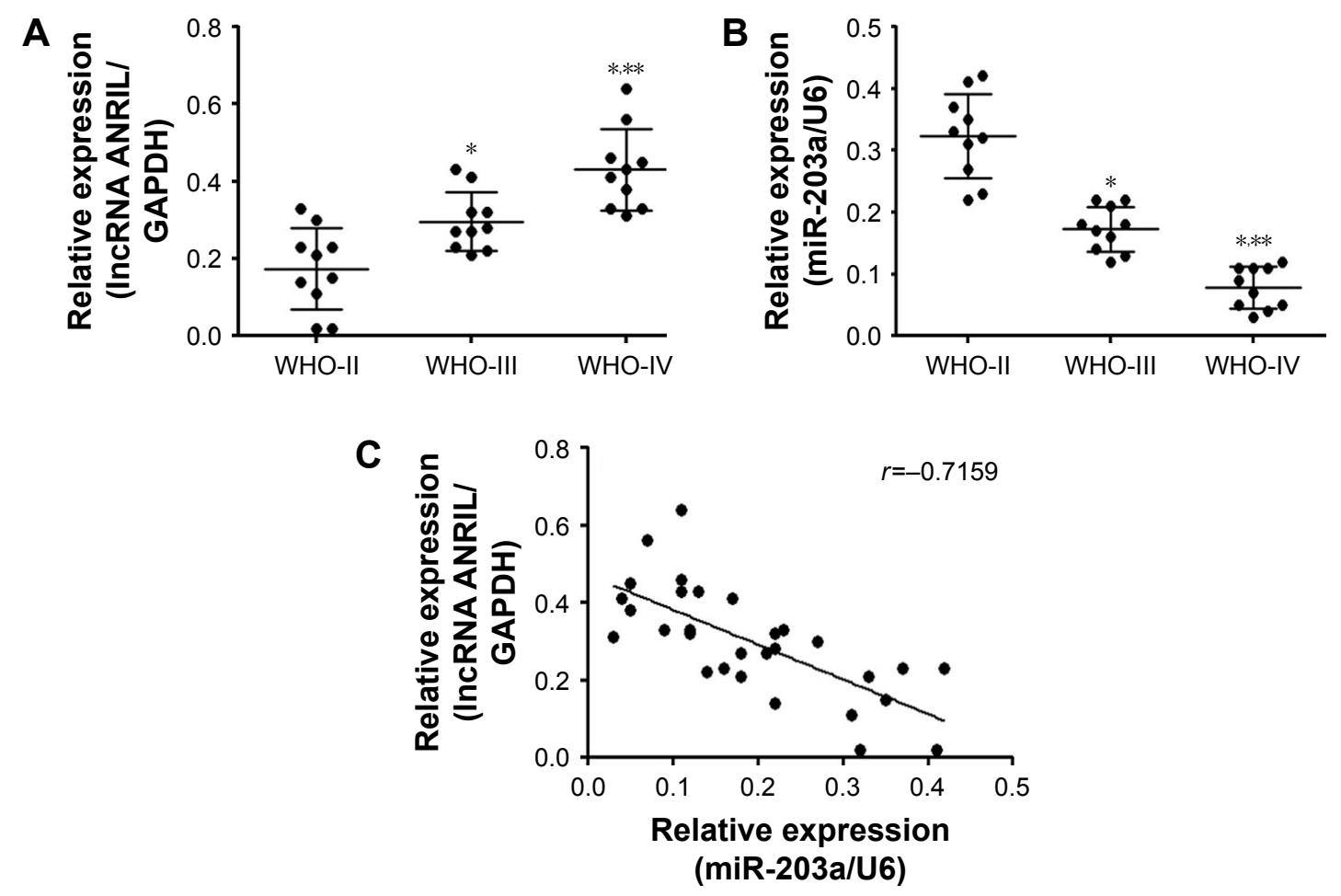

Figure I Expression of IncRNA ANRIL and miR-203a in glioma tissues.

Notes: (A) Increased expression of IncRNA ANRIL in glioma tissues correlating with tumor grade. (B) Decreased expression of miR-203a in glioma tissues correlating with tumor grade. (C) Negative correlation between IncRNA ANRIL and miR-203a in glioma tissues. *Compared with negative control group, $P<0.05$; ** compared with si-ANRIL group, $P<0.05$.
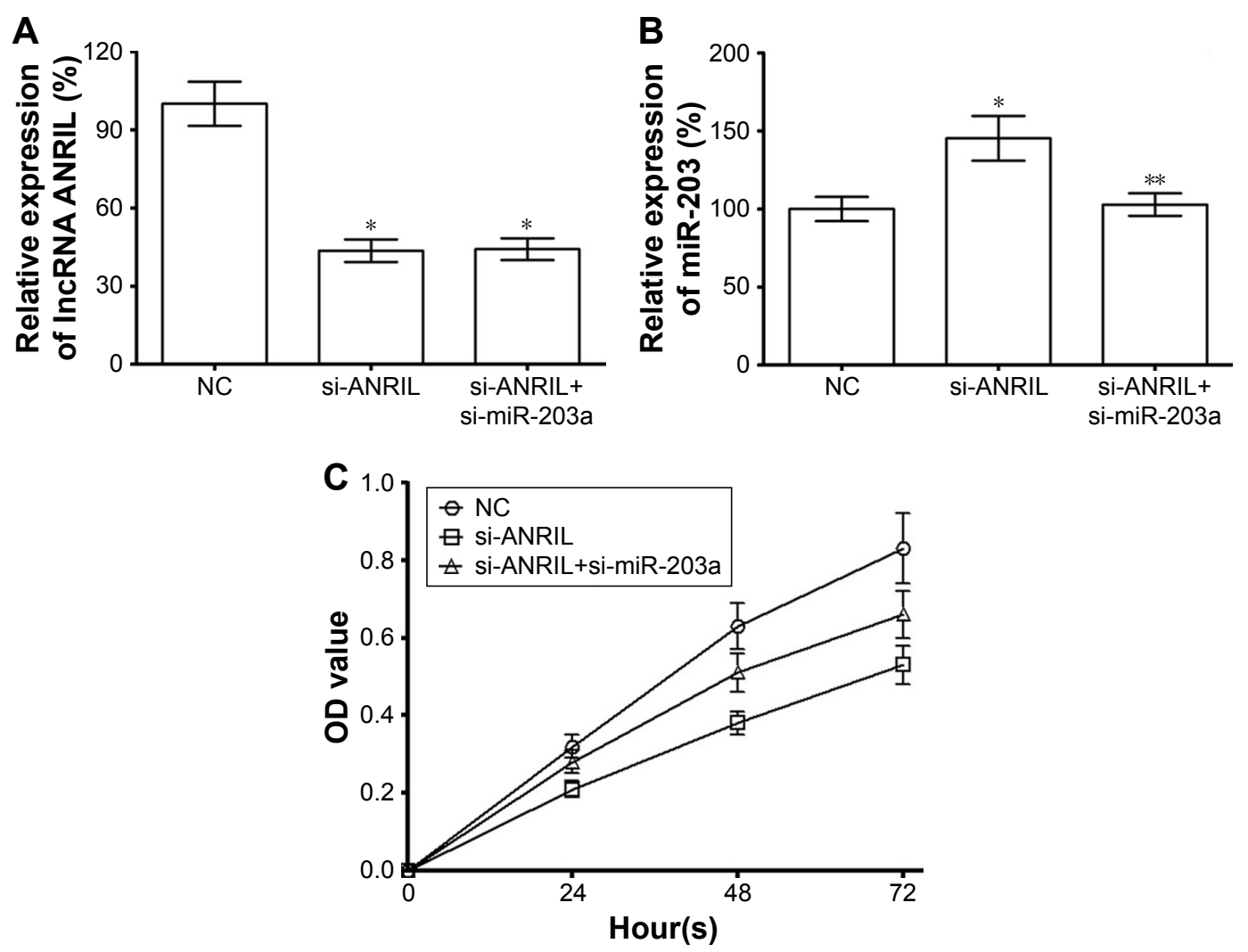

Figure 2 Effect of IncRNA ANRIL silencing on the proliferation of U25I cells.

Notes: (A) Decreased expression of IncRNA ANRIL in IncRNA ANRIL silenced U25I cells; miR-203a mimics could not reverse the decreased expression. (B) Increased expression of miR-203 in IncRNA ANRIL silenced U25I cells; miR-203a mimics could reverse this increased expression. (C) Decreased proliferation of IncRNA ANRIL silenced U25I cells; miR-203a mimics could partially reverse this decrease. *Compared with negative control (NC) group, $P<0.05$; $* *$, compared with si-ANRIL group, $P<0.05$. 
A

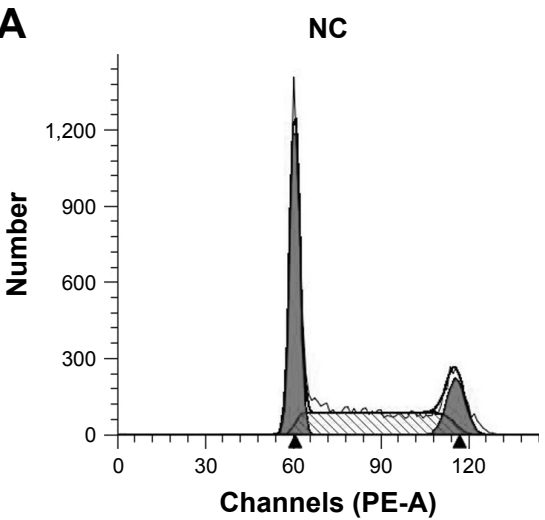

si-ANRIL

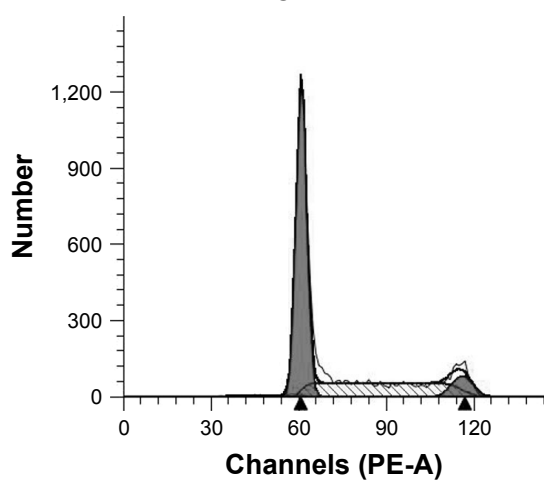

si-ANRIL+si-miR-203a

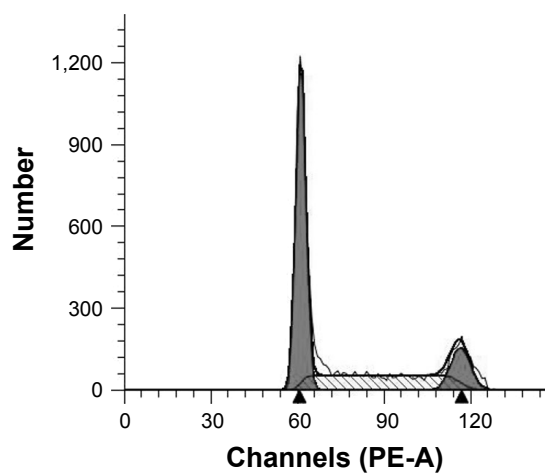

B

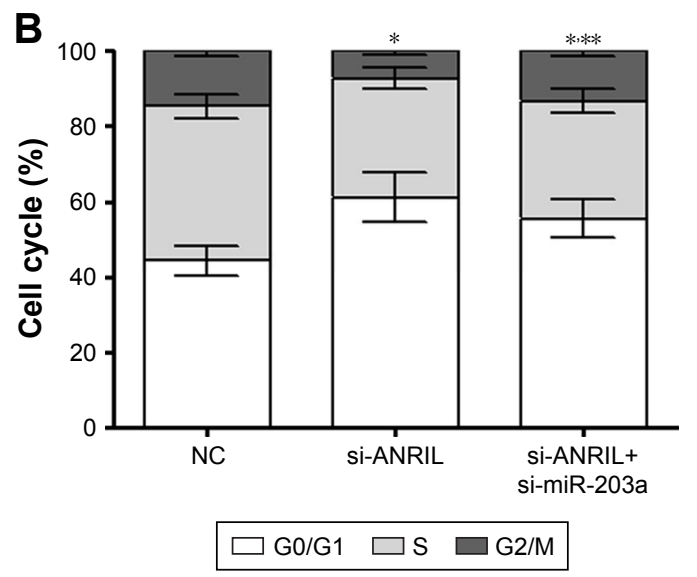

C

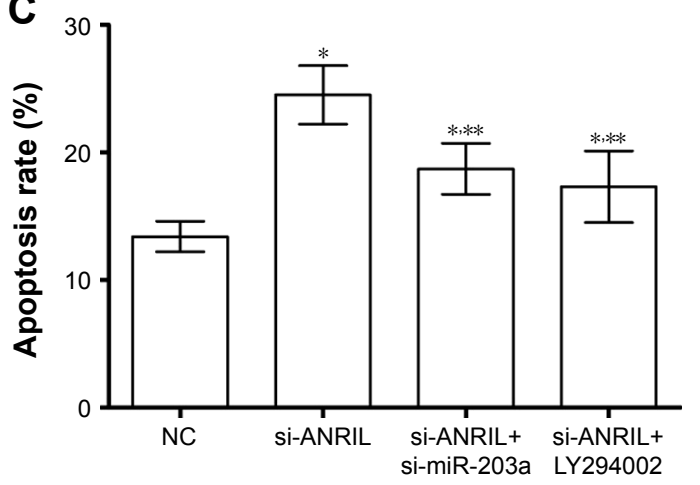

Figure 3 Effect of IncRNA ANRIL silencing on anoikis and cell cycle in U25I cells.

Notes: (A) G0/GI phase arrest in IncRNA ANRIL silenced U25I cells; miR-203a mimics could partially reverse this arrest. (B) Cell cycle in IncRNA ANRIL silenced U25I cells. (C) Increased anoikis in IncRNA ANRIL silenced U25I cells; miR-203a mimics could partially reverse this increase. ${ }^{*}$ Compared with negative control (NC), $P<0.05$; ***ompared with si-ANRIL group, $P<0.05$.

\section{Discussion}

There are a large number of ncRNAs in the human genome. ${ }^{8}$ Although ncRNAs do not encode proteins, they can regulate the expression of miRNAs and their biological function. IncRNAs are a type of ncRNA and play an important role in the tumorigenesis process. ${ }^{9}$ lncRNA ANRIL is overexpressed in osteosarcoma and lung cancer; however, the role and biological mechanism of lncRNA ANRIL in glioma have not been fully understood. We found that there was an increased expression of IncRNA ANRIL in glioma tissue samples, positively correlated with grade. Meanwhile, the expression of lncRNA ANRIL was negatively correlated with the anti-oncogene miR-203a. Further, we also silenced lncRNA ANRIL in glioma U251 cells and observed that lncRNA ANRIL silencing could induce anoikis and cell cycle arrest in G0/G1 phase in U251 cells.

$B c l-2$ is an anti-apoptosis gene that can suppress the activity of caspase. ${ }^{10} \mathrm{We}$ found that lncRNA ANRIL silencing could suppress the expression of $B c l-2$ in U251 cells; meanwhile, the activity of caspase-3/8/9 was up-regulated. $C D K 2$ is a cell cycle related gene, ${ }^{11}$ and we found that
IncRNA ANRIL silencing could suppress the expression of CDK2 in U251 cells. $p 21$ is a tumor suppressor gene that can induce apoptosis by regulating $\mathrm{Bcl}-2,{ }^{12}$ and induce cell cycle arrest by regulating CDK2 in tumors. ${ }^{13} c$-myc is also an oncogene that can negatively regulate the expression of p21. ${ }^{14}$ We found that lncRNA ANRIL silencing could suppress the expression of $c-m y c$ and improve the expression of $p 21$.

AKT is an important signaling molecule in the tumorigenesis process and shows increased expression in tumors. ${ }^{15}$ Twist1 and c-jun are transcription factors that are downstream signaling molecules of the AKT pathway and are up-regulated in tumors. ${ }^{16,17}$ We found that lncRNA ANRIL silencing could suppress the phosphorylation of AKT and the transcriptional activity of Twist 1 and $c$-jun, indicating lncRNA ANRIL could regulate the tumorigenesis process by regulating the phosphorylation of AKT and the transcriptional activity of Twist 1 and c-jun in U251 cells. We also found that the anoikis induced by lncRNA ANRIL was partially suppressed by LY294002, a PI3K inhibitor, certifying the role of AKT in anoikis mediated by lncRNA ANRIL. 

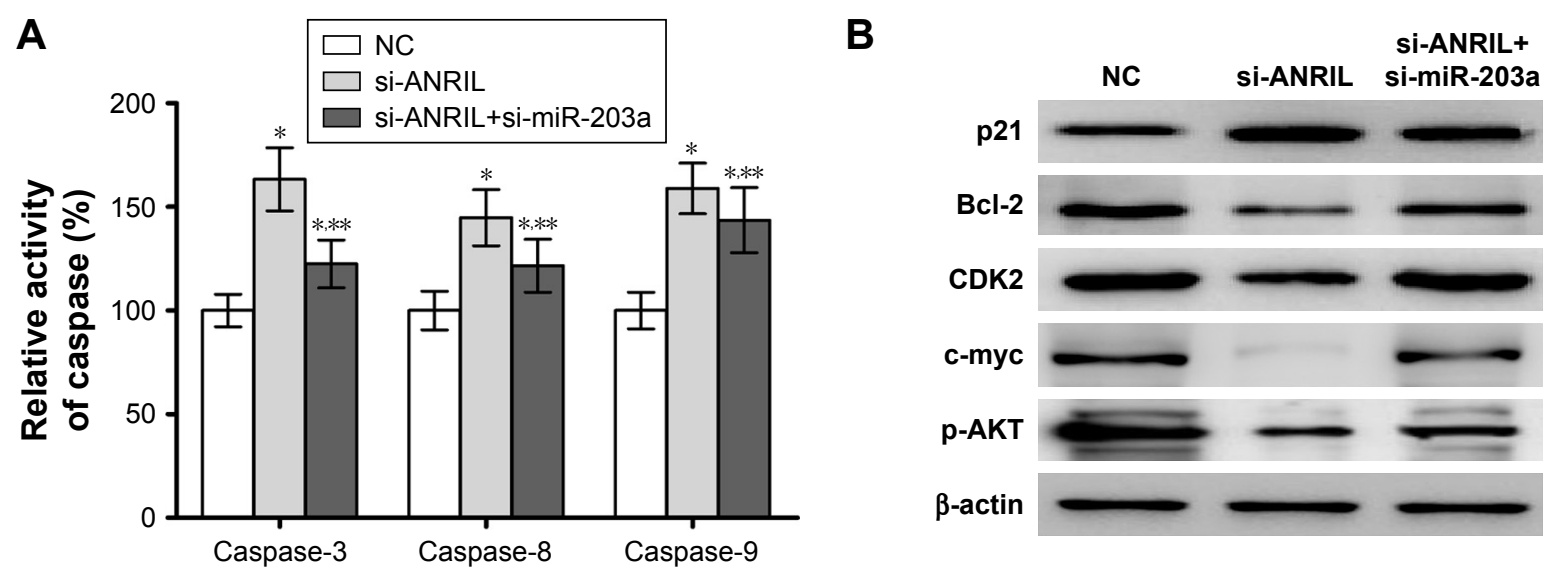

C

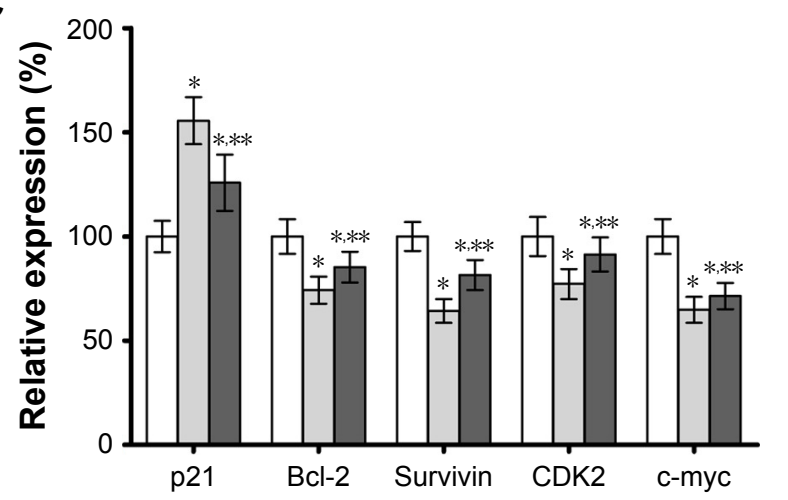

D

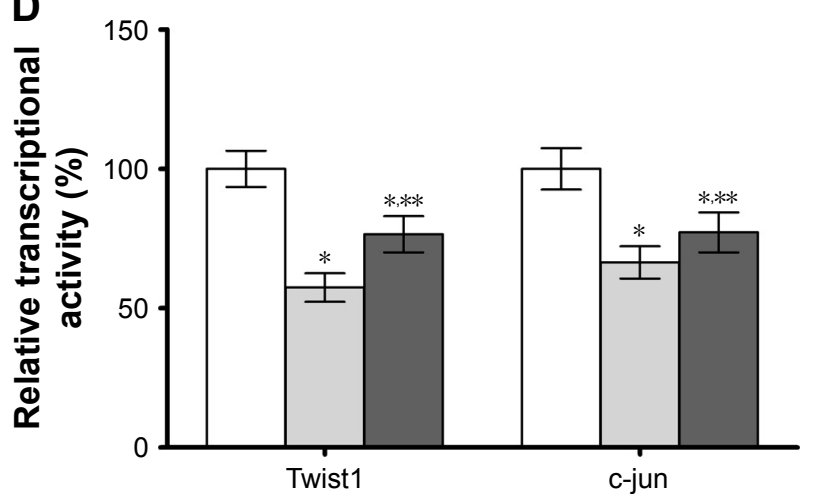

$\square$ NC $\square$ si-ANRIL $\square$ si-ANRIL+si-miR-203a

Figure 4 Effect of IncRNA ANRIL silencing on the activity of caspase and expression of tumor-related genes in U25I cells.

Notes: (A) Increased activity of caspase-3/8/9 in IncRNA ANRIL silenced U25 I cells; miR-203a mimics could partially reverse this increase. (B) Increased expression of p2 I protein and decreased expression of Bcl-2, CDK2, c-myc, and p-AKT proteins in IncRNA ANRIL silenced U25I cells; miR-203a mimics could partially reverse this effect. (C) Increased expression of $p 21$ mRNA and decreased expression of Bcl-2, CDK2, and c-myc mRNA in IncRNA ANRIL silenced U25I cells; miR-203a mimics could partially reverse this function. (D) Decreased transcriptional activity of Twist I and c-jun in IncRNA ANRIL silenced U25I cells; miR-203a mimics could partially reverse this decrease. *Compared with negative control (NC) group, $P<0.05$; ** compared with si-ANRIL group, $P<0.05$.

miR-203a is an anti-oncogene that is overexpressed in tumors, and we also found decreased expression in glioma tissues. We found that lncRNA ANRIL silencing could improve the expression of miR-203a, and miR-203a mimics could partially reverse this effect. The result showed that lncRNA ANRIL affected the oncogenic function via miR-203a.

\section{Disclosure}

The authors report no conflicts of interest in this work.

\section{References}

1. Chen J, Wu X, Xing Z, et al. FOXG1 Expression Is Elevated in Glioma and Inhibits Glioma Cell Apoptosis. J Cancer. 2018;9(5):778-783.

2. Zhu Y, Zhang X, Qi L, et al. HULC long noncoding RNA silencing suppresses angiogenesis by regulating ESM-1 via the PI3K/Akt/ mTOR signaling pathway in human gliomas. Oncotarget. 2016;7(12): 14429-14440.

3. Zhou J, Xiang W, Li S, et al. Association between long non-coding RNAs expression and pathogenesis and progression of gliomas. Oncol Lett. 2018;15(4):4070-4078.
4. Yu G, Liu G, Yuan D, Dai J, Cui Y, Tang X. Long non-coding RNA ANRIL is associated with a poor prognosis of osteosarcoma and promotes tumorigenesis via PI3K/Akt pathway. J Bone Oncol. 2018; 11:51-55.

5. Xie Y, Zhang Y, Du L, et al. Circulating long noncoding RNA act as potential novel biomarkers for diagnosis and prognosis of non-small cell lung cancer. Mol Oncol. 2018;12(5):648-658.

6. Zang J, Hui L, Yang N, Yang B, Jiang X. Downregulation of MiR-203a Disinhibits Bmil and Promotes Growth and Proliferation of Keratinocytes in Cholesteatoma. Int J Med Sci. 2018;15(5):447-455.

7. Gomes BC, Martins M, Lopes P, et al. Prognostic value of microRNA203a expression in breast cancer. Oncol Rep. 2016;36(3):1748-1756.

8. Vallone C, Rigon G, Gulia C, et al. Non-Coding RNAs and Endometrial Cancer. Genes. 2018;9(4):187.

9. Wang Z, Pan L, Yu H, Wang Y. The long non-coding RNA SNHG5 regulates gefitinib resistance in lung adenocarcinoma cells by targeting miR-377/CASP1 axis. Biosci Rep. Epub 2018 Mar 28.

10. Ju X, Yu H, Liang D, et al. LDR reverses DDP resistance in ovarian cancer cells by affecting ERCC-1, Bcl-2, Survivin and Caspase-3 expressions. Biomed Pharmacother. 2018;102:549-554.

11. Guo E, Liang C, He X, et al. Long Noncoding RNA LINC00958 Accelerates Gliomagenesis Through Regulating miR-203/CDK2. DNA Cell Biol. 2018;37(5):465-472.

12. Kang M, Xia P, Hou T, Qi Z, Liao S, Yang X. MicroRNA-190b inhibits tumor cell proliferation and induces apoptosis by regulating Bcl-2 in U2OS osteosarcoma cells. Pharmazie. 2017;72(5):279-282. 
13. Liu Z, Liu H, Yuan X, et al. Downregulation of Pim-2 induces cell cycle arrest in the G0/G1 phase via the p53-non-dependent p21 signaling pathway. Oncol Lett. 2018;15(4):4079-4086.

14. Dorasamy MS, Choudhary B, Nellore K, Subramanya H, Wong PF. Dihydroorotate dehydrogenase Inhibitors Target c-Myc and Arrest Melanoma, Myeloma and Lymphoma cells at S-phase. J Cancer. 2017; 8(15):3086-3098.

15. Wang Y, Wang H, Ge H, Yang Z. AG-1031 induced autophagic cell death and apoptosis in C6 glioma cells associated with Notch-1 signaling pathway. J Cell Biochem. 2018;119(7):5893-5903.
16. Nam EH, Lee Y, Moon B, Lee JW, Kim S. Twist1 and AP-1 cooperatively upregulate integrin $\alpha 5$ expression to induce invasion and the epithelial-mesenchymal transition. Carcinogenesis. 2015;3:327-337.

17. Xie W, Zhang Z, Song L, et al. Cordyceps militaris Fraction induces apoptosis and G2/M Arrest via c-Jun N-Terminal kinase signaling pathway in oral squamous carcinoma KB Cells. Pharmacogn Mag 2018;14(53):116-123.

\section{Publish your work in this journal}

OncoTargets and Therapy is an international, peer-reviewed, open access journal focusing on the pathological basis of all cancers, potential targets for therapy and treatment protocols employed to improve the management of cancer patients. The journal also focuses on the impact of management programs and new therapeutic agents and protocols on

\section{Dovepress}

patient perspectives such as quality of life, adherence and satisfaction. The manuscript management system is completely online and includes a very quick and fair peer-review system, which is all easy to use. Visit http://www.dovepress.com/testimonials.php to read real quotes from published authors.

Submit your manuscript here: http://www.dovepress.com/oncotargets-and-therapy-journal 